Commentary on Maria and Andrea: Comparing Positive and Negative Outcome Cases in an Online, Clinician-Guided, Self-Help Intervention for Panic Disorder; and

Daydreamer and Night Owl: Comparing Positive and Negative Outcome Cases in an Online, Clinician-Guided, Self-Help Intervention for Social Anxiety Disorder

\title{
Why Do Some Psychotherapy Clients Get Better Than Others?
}

\section{TRACY D. EELLS ${ }^{a, b}$}

${ }^{\mathrm{a}}$ Department of Psychiatry and Behavioral Sciences, University of Louisville

b Correspondence regarding this article should be sent to Tracy D. Eells, University of Louisville, Department of Psychiatry \& Behavioral Sciences, 401 East Chestnut Street, Suite 610, Louisville, KY 40202

Email: tracy.eells@louisville.edu

\begin{abstract}
This commentary explores reasons why one client's outcome was better than the other's in two comparative case studies: the cases of "Maria" and "Andrea," involving panic disorder (Ciuca, Berger, \& Miclea, 2017); and the cases of "Daydreamer” and "Night Owl,” involving social anxiety (Schulz, Vincent, \& Berger, 2017). Findings suggest that both specific and common factors may explain the difference. Specific factors include the extent to which exteroceptive exposure was implemented and avoidant behaviors were relaxed. Common factors that may explain the difference in outcome include acceptance of the treatment model, number of success experiences, perceived self-efficacy, and the logical link between the client's explanation of problems and the treatment offered.
\end{abstract}

Key Words: Panic Disorder; Social Anxiety Disorder (SAD); Internet-Based CBT Treatment (ICBT); cognitive-behavioral treatment; guided self-help; cross-case analysis; clinical case studies; case studies

The case studies of "Maria” and “Andrea” involving panic disorder (Ciuca, Berger, \& Miclea, 2017), and of "Daydreamer" and "Night Owl” involving social anxiety (Schulz, Vincent, \& Berger, 2017), are good examples of the "Case Studies Within Psychotherapy Trials” (CWT) mixed-methods research model described by Fishman, Messer, Edwards, and Datillio (2017). The case studies extend the application of the approach by examining positive and negative outcomes in the burgeoning area of computer-assisted psychotherapy (Arnberg, Linton, Hultcrantz, Heintz, \& Jonsson, 2014) while also affording the opportunity to explore a key claim made of the CWT mixed-models approach. As Fishman and colleagues (2017) write, ”The mixed-methods model provides an epistemological rationale for combining research methods that generate what are in effect different kinds of knowledge, and it offers guidelines for integrating the two kinds of methods within a single research study. By combining both types of data, researchers gain a more differentiated and trustworthy overall picture of the phenomenon being studied" (p. 8). 
Randomized clinical trials (RCT) are designed to answer questions such as, "Is treatment A effective?", "Is treatment A better than treatment B for condition X?", and "What components of treatment A are most effective?” RCTs answer these questions only in reference to the average treatment response, not to any particular client or certainly not to all individual clients receiving treatment within the RCT. In contrast, systematic, qualitative case studies permit researchers to examine questions such as, "Why did clients $\mathrm{A}, \mathrm{B}$, and $\mathrm{C}$ in the experimental condition have successful outcomes?" and "Why did clients D, E and F have unsuccessful outcomes?" Systematic case studies permit analysis of client-specific questions such as these by facilitating a close examination of therapy process-to-outcome connections as the therapy unfolds (Fishman, 1999). In some instances, assert Fishman and colleagues (2017), systematic case studies may also provide a rigorous test of theory (Fishman et al., 2017, p. 16).

The primary goal of this commentary is to focus on process-to-outcome connections in order to answer the question, "Why did one client achieve a better outcome than the other?" in each of the two sets of case studies. We will do so by examining the theory underlying each treatment, then assess how well the theory and the specific interventions that flow from it explain the course each therapy took. We will also consider other explanations based on a common factors perspective, and alternative theories that might explain the outcome. (For somewhat different perspectives on generalizing knowledge about psychotherapy from pragmatic case studies, see Eells (2007) and Stiles (2009).)

\section{PANIC DISORDER}

\section{Theory of the Cases}

Ciuca Berger, and Micleae (2017) explain that the "PAXonline” Internet-based treatment program for panic disorder was developed de novo based on empirically supported cognitivebehavioral models initially proposed by Craske and Barlow (2014), Andrews (2003), Clark and Beck (2011), and Leahy and Holland (2000). These models conceptualize panic disorder as an acquired fear of bodily sensations, especially sensations arising from autonomic nervous system arousal. Psychological and biological factors are thought to increase vulnerability to panic disorder. These include a genetic predisposition to experience anxiety and negative affect, early life experiences that produce a diminished sense of control over one's environment, and powerful learning experiences that focus anxiety on particular areas of concern. More particularly, certain somatic sensations become associated with an intensely elevated sense of fear and threat. Fear conditioning, avoidant responding (or "safety behaviors"), and information-processing biases are conceptualized as maintaining factors (Craske \& Barlow, 2014).

The above conceptualization appears to fit both "Maria," a client with a positive outcome, and "Andrea," a client with a less positive outcome. Both clients described anxious caretakers and themselves as anxious and "sensitive" all or most of their lives, and thus likely had a predisposition toward anxiety symptoms. Although both reported happy childhoods, evidence suggests challenging developmental experiences for both. Maria was raised by a single mother and grandparents; her father never recognized her as his daughter. Andrea's 
failure to establish psychological independence from her parents, her feeling of being “completely abandoned” after her father died, and her inability to establish warm and lasting intimate relationships as an adult all suggest developmental challenges and memory biases that may color her retrospective view of childhood. Both Maria and Andrea experienced heightened sensitivity to autonomic cues that were frightening and which they interpreted catastrophically. Both also made extensive use of avoidant behaviors, for example, isolating themselves at home and only venturing outside when accompanied by a trusted companion.

Ciuca and colleagues report many other ways in which Maria and Andrea presented similarly. Both experienced initial panic attacks at times when they faced particularly difficult circumstances. Maria was breaking up with a boyfriend and was exhausted from a stressful week as a waitress. Her mother gave her a Xanax when her first attack started, but it only seemed to escalate the symptoms to the point of a full-blown attack. Andrea's first attack occurred months after two significant interpersonal losses - the death of her father and her sister moving to another city. Andrea's attacks were sometimes triggered by cervical spondylosis, which gave her headaches, pressure in her head, dizziness, and the feeling that she might pass out. Both Maria and Andrea scored similarly on pretreatment measures of symptoms of panic disorder, anxiety, sensitivity to bodily sensations, depression symptoms, and global functioning. Both met criteria for severe panic disorder with agoraphobia, depression, and generalized anxiety disorder. Both felt they needed to be accompanied when leaving home and both isolated themselves at home. Further, the onset of the panic attacks was relatively recent. Maria's was 8 months before treatment and Andrea's was 7 months.

Maria and Andrea both received the same treatment model. Although both benefited meaningfully from treatment, especially when considering data gathered at the one-month and three-month follow-up assessments, Maria clearly benefited much more than did Andrea, begging the question of why. It is to that question that we now turn.

\section{Why Was Maria's Treatment More Successful Than Andrea's?}

\section{Compliance with Therapy}

The most parsimonious way to explain the differential treatment outcomes is to begin by asking whether Maria and Andrea complied comparably with treatment. As noted, the treatments flow directly from the cognitive-behavioral theory that panic disorder is an acquired maladaptive fear and misinterpretation of somatic sensations of autonomic arousal, maintained by learned avoidance-or "safety"-behaviors. If the theory is correct, and it is tied directly to the treatment, then successful implementation of the treatment should lead to symptom relief.

In the cases of Maria and Andrea, the use of a computerized program that delivers the content of empirically supported treatments -and ensuring its use by clients-provides meaningful evidence that an empirically supported treatment was delivered in a high quality manner. Both Maria and Andrea used the PAXonline program for panic disorder extensively. Maria used all the recommended modules at least once or twice, spending a total of 425 minutes on the platform — and also completed most of the required worksheets. Andrea went through all 
the modules at least twice and in some cases five times, and she also uploaded most of the worksheets. She spent a total of 1020 minutes on the platform. Both also made extensive use of the Skype interviews, although Andrea used more therapist time than did Maria (434 minutes as compare to 312).

One difference is that Andrea practiced exposure exercises with less frequency than did Maria, only for about two weeks ( 2 or 3 times per week.) Further, most of these were interoceptive exercises, rather than exteroceptive exposure. In contrast, Maria appeared to embrace all exposure exercises - both the interoceptive and exteroceptive-despite her fear and some setbacks. Another possible difference, one related to exposure, is how Maria and Andrea managed their counterproductive avoidance behaviors. Both read and learned about them, but Maria appeared to have been more willing to challenge them behaviorally.

In sum, with the exception of exposure exercises - which are known to be effective in treating anxiety (Crits-Christoph, Gibbons, \& Mukherjee, 2013)_and their readiness to let go of their safety behaviors, Maria and Andrea appear to have implemented the treatment techniques similarly.

\section{$\underline{\text { Common Factors }}$}

A next step in seeking an explanation of the difference in outcomes is to explore the extent to which factors shared across all therapies and which are known to be effective, were successfully implemented. As Lambert (2013) writes, common factors account for about 30\% of improvement in psychotherapy clients. There are many ways to approach this question and several common factors one can focus on. One place to start is to look at the quality of the therapeutic alliance. Based on the Bond subscale of the Working Alliance Inventory (WAI), both Maria and Andrea enjoyed very positive bonds with their therapists. So, strength of the therapeutic alliance, a process variable that correlates on average .22 with outcome (Martin, Garske, \& Davis, 2000), does not appear to explain the difference in outcome.

Other common factors are those that reside within the client. Considerable evidence shows that characteristics of the client play the most important role in making psychotherapy work (Bohart \& Wade, 2013; Orlinsky, Grawe, \& Parks, 1994). These include a willingness to face one's fears, a willingness to take risks, the achievement of success experiences, a capacity for behavioral/emotional regulation, and mastery efforts (Lambert, 2013). Others are secure attachment, lower self-criticism, motivation, and the match between a client's reactance and characteristics of the treatment. We are left to speculate on some of these factors in understanding Maria and Andrea, although there is evidence that both were highly motivated and were relatively low reactant individuals, the latter of which fits well with the prescriptive, manualized nature of the Internet-based treatment.

With regard to attachment, Andrea may have a more insecure attachment style than Maria. She lived with her mother, was not in an intimate relationship, does not have a history of close interpersonal relationships, and was described by her therapist as possibly having a dependent personality disorder. On the other hand, although they argued, Maria is described as 
in a supportive relationship with her boyfriend (although it is not clear whether this is the same person she was breaking up with when her first panic attack happened.)

Regarding willingness to face fears and make efforts at mastery, I have already noted that Maria may have exceeded Andrea in these areas, as demonstrated by her subjecting herself to more exteroceptive exposure experiences. These efforts appear to be temporally tied to success experiences she enjoyed shortly after taking these risks, which in turn countered her maladaptive thought patterns and gave her more courage and confidence to take more risks. Evidence suggests that enhancing self-efficacy can lead to more effective cognitive-behavioral interventions for those with anxiety, including agoraphobia (Williams, 1990; Williams, Dooseman, \& Kleifield, 1984). As an adjunct to the treatment she received, Andrea may have benefited from guided mastery therapy, which is aimed at enhancing self-efficacy (Scott \& Cervone, 2009). It should be noted that the authors observe that Maria appears to have been at a different stage of readiness to change than was Andrea. A further difference could be the medical problems Andrea faced, which may have further heightened her sensitivity to interoceptive cues.

\section{Frank and Frank’s (1991) Approach to Common Factors}

Another way to examine the treatments through the lens of common factors is to consider each in terms of the four characteristics that the comparative study of Frank and Frank (1991) found as common to all therapies and as accounting for much of their effectiveness. The first is that an emotionally charged and confiding relationship is developed between a client and a therapist. We have already discussed that this characteristic was the case for both Maria and Andrea, as measured by the WAI.

The second shared characteristic is that the therapeutic relationship unfolds in a circumscribed, culturally sanctioned context in which clear roles are played by each participant: the client presents as a suffering individual and the therapist presents as a professional trained to help. Here again, there are no differences between the treatment received by Maria and by Andrea. As an aside, this characteristic would not have been met had the cases been drawn from the arm of the RCT in which the computer program delivered the therapy with no therapist involvement. It would be interesting to study clients' "relationship" with the computer under this condition.

The third shared characteristic is that a credible and persuasive account of the reasons for the client's symptoms and problems is collaboratively accepted by the client and therapist, including a treatment plan that flows from the account. Maria and Andrea may differ in regard to this characteristic. Although both began with some skepticism that treatment would work, Maria quickly accepted the explanatory model of her panic attacks and was "very motivated" (p. 187), "curious" (p. 187), and "eager to find out more about her problems and how she could reduce them” (p. 187). When the explanatory model was presented to her in her first Skype session, she commented, "I understand everything. That's exactly what happened to me" (p. 187). 
On the other hand, Andrea's skepticism appears to have been greater and to have persisted throughout the treatment, as shown by her scores on the Credibility Questionnaire and the Expectancy Questionnaire. Further evidence that Andrea may not have accepted the treatment as fully as Maria is shown in Andrea's much lower scores on the System Usability Scale, whereas Maria found the Online program much more usable.

The fourth and final common factor identified by Frank and Frank is that both the client and therapist actively engage in treatment. We have already discussed the similarities and possible differences in regard to engagement in all aspects of treatment.

In sum, a review of Frank and Frank's four common factors of psychotherapy suggests that one factor to consider in explaining the different outcomes is that Andrea may not have accepted the treatment rationale as fully as Maria.

\section{$\underline{\text { Considering an Alternative Treatment Model }}$}

Another explanation to consider when trying to understand the different outcomes achieved by Maria and Andrea is that the treatment model offered to Andrea was not best suited to her overall presentation, and that an alternate model may have better suited her needs. One empirically supported alternate model is panic-focused psychodynamic psychotherapy (PFPP), which has demonstrated efficacy in treating panic disorder (Milrod et al., 2015). This model assumes that panic symptoms have psychological meaning. The goal of therapy is to uncover the unconscious meaning through a process of reflection to achieve relief. Clients are invited to explore circumstances and feelings surrounding the initial and subsequent panic attacks, including the meanings of panic symptoms. Common psychodynamic conflicts explored relate to separation and autonomy; recognizing, managing, and coping with anger; and panic as an expression of guilt. The approach seeks to lessen vulnerability to panic attacks by helping clients understand and alter core unconscious conflicts, which are thought to emerge in the transference. Termination permits clients to re-experience conflicts directly with the therapist so that underlying feelings can be articulated and become less frightening. Termination is aggressively addressed in the final third of treatment (Milrod et al., 2015).

While it obviously requires speculation to imagine how Andrea's therapy would have unfolded were she offered PFPP, a review of her history indicates the relevance of themes identified by this approach, particularly that of separation and autonomy. This claim is supported by the following evidence: (1) the onset of panic symptoms occurred shortly after the death of her father, which she experienced as a complete abandonment, and the relocation of her sister; (2) the absence of a close intimate relationship and no history of her ever having had one; and (3) her high degree of dependence on her therapist to the point that he thought she may have Dependent Personality Disorder. It is not clear from the information presented whether anger management or guilt are prominent themes for Andrea. It would be interesting to learn how Andrea would fare under a course of PFPP, having already undergone the PAXonline treatment. The Online modality of the latter helped her and she may have been unwilling to venture out of her home to meet with a therapist to engage in PFPP without an initial experience of the PAXonline treatment to build her confidence. 
In sum, this analysis suggests that the following factors may explain Andrea's worse outcome, compared to that of Maria: (1) failure to engage more in exteroceptive exposure exercises and less willingness to reduce her maladaptive avoidance mechanisms; (2) the presence of medical illness that catalyzed panic attacks; (3) lower perceived self-efficacy; (4) more problems in achieving secure attachments; (5) doubt about the therapy explanatory model; (6) not as ready to change; and (7) possibly the delivery of a model that was not best suited to her presentation.

In the following section, we will perform the same exercise for the two social phobia cases, although in a more abbreviated manner.

\section{SOCIAL ANXIETY DISORDER}

\section{Theory of the Cases}

Schulz, Vincent and Berger (2017) report that their Online, clinician-guided program to treat social anxiety disorder is based on the treatment model developed by Clark and Wells (1995). As Clark and Wells explain, "the core of social phobia appears to be a strong desire to convey a particular favorable impression of oneself to others and marked insecurity about one's ability to do so" (p. 69). When entering a social situation perceived as fearful, those with social anxiety disorder believe they are in danger of behaving in an inept and unacceptable fashion and that their behavior will result in loss of status, loss of worth, and rejection. When a social situation is thus interpreted, a constellation of cognitive, somatic, affective, and behavioral changes are triggered to protect the individual from perceived harm.

A vicious circle is thus established in which the responses to perceived threat are themselves interpreted as threatening ("If they see I'm sweating, I’ll be humiliated”), and consequently maintain or exacerbate anxiety, as well as interfere with processing social cues. The individual may "freeze" inwardly appearing aloof to others and elicit less warmth and friendliness. Further, the somatic and behavioral symptoms may trigger additional sensations, for example, hyperventilation, tachycardia, or dizziness.

Clark and Wells say little about the etiology and diatheses of social anxiety disorder, except that they occur "as a consequence of previous experience interacting with innate behavioral predispositions” (p. 69). In more recent work, Barlow has proposed that similar processes as those producing panic disorder also produce social phobia (Barlow, 1988, 2002; Suárez, Bennett, Goldstein, \& Barlow, 2008). Barlow, Allen, and Basden (2007) review evidence for this theory.

Schulz et al.’s (2017 positive outcome case, "Daydreamer," and their negative outcome case, "Night Owl," describe their experiences in ways that fit the Clark and Wells model of social anxiety. Both fear social and performance situations and try to avoid them for fear of rejection. Both also experience physiological symptoms and interpret social situations in ways that are maladaptive. Further, both report longstanding problems with social anxiety, as well as problems with their self-concept. Daydreamer feels he is "weird," "socially inept and clumsy." Night Owl feels he is "weak" and is a perfectionist. Both also report longstanding experiences 
of shyness and introversion, both on their part and on the part of biological relatives. Daydreamer traced the onset of social anxiety to being bullied as a child. Night Owl could not identify a precipitant, but described his mother as overprotective and his father as highly critical and as demanding, which could serve as a specific psychological vulnerability in the Barlow model. Further, his recent exacerbation of symptoms appears precipitated by the stress of a divorce and a promotion at work.

Daydreamer and Night Owl fit the Clark and Wells model and received Online, clinicianguided cognitive-behavioral treatment designed to address the hypothesized causes and maintaining factors of their social anxiety, yet the outcomes were quite different. As with Maria and Andrea, we are again faced with the question, "Why were the outcomes so different?"

\section{Why Was Daydreamer's Treatment More Successful Than Night Owl's?}

\section{Compliance with Treatment}

As with the panic disorder cases, we will begin our examination of why Daydreamer fared better than Night Owl by examining how well the treatment protocol was implemented and adhered to by each client. Both clients used the program thoroughly. However, Daydreamer appears be a textbook example of excellent process and outcome. He was highly motivated, had compelling reasons to change, and engaged actively in all elements of the treatment. He practiced progressive muscle relaxation almost daily, and it relaxed him. He made excellent use of the on-line diary, gaining insight into the multiple details and ramifications of his social anxiety. His therapist's emails were motivating. He received information about cognitive restructuring almost as a revelation, exclaiming it was "no wonder" (p. 229) his negative thoughts of himself and his behavior made him feel so badly. He disclosed difficulties to his therapist as they arose, for example, with the self-focused attention exercises, and appears to have followed advice that was given. While he struggled initially and understandably with the exposure component of treatment, he followed through with it. As a result, he gained more and more confidence and attempted more and more challenging tasks, which further built his confidence and sense of mastery.

Night Owl, on the other hand, was much more ambivalently motivated despite his engagement with the program. His explanatory model for his social anxiety attributed causes to the treatment he received from his parents as a child. This explanation, however, had tenuous links at best to the treatment he received. He found the psychoeducation material helpful, but apparently had been aware of much of it prior to treatment, and thus it did not enhance motivation. His use of the cognitive restructuring module drifted away from a focus on his social anxiety to other dysfunctional assumptions, which may have diluted the impact of this module on helping him with social anxiety. He did not use the exposure exercises to his best advantage, maintaining his safety mechanism of keeping others at a distance while on dates. He continued to confront several other difficult situations from his exposure hierarchy, and gained greater perceived self-efficacy as a result, but he did not experience his overall anxiety as decreasing significantly. It is not clear why he continued to feel anxious. He may have continued to distance others and may also not have brought to bear the full benefit of the 
cognitive restructuring exercises. Evidence supporting these conjectures is in his notes in which he described "different kinds of covert avoidance or safety behavior strategies" (p. xx). Overall, Night Owl did gain from the treatment protocol, perhaps commensurate to the extent that he allowed himself to engage in the treatment.

\section{Common Factors}

From a common factors perspective, Daydreamer bonded well with his therapist, was motivated, experienced success early and built on it despite a setback as he prepared himself for the exposure component of treatment. Night Owl, on the other hand, was ambivalently motivated and it is not clear that he fully accepted the explanatory model for the treatment he received. He was also more reluctant to take risks, but he did bond well with his therapist. Like Andrea, he may have benefited from self-efficacy enhancing treatment to facilitate fuller engagement in the exposure components of the treatment as well fuller use of the cognitive restructuring module to support the exposure tasks.

\section{$\underline{\text { Considering an Alternative Treatment Model }}$}

Cognitive-behavioral treatment for social anxiety disorder is currently the only treatment recognized as empirically supported by Division 12 of the American Psychological Association (https://www.div12.org/, as documented in the "Psychological Treatments" section under the "Resources" tab). Nevertheless, it is worthwhile considering alternative models. Leary and Kowalski (1995) offer a self-presentation model of social anxiety. They identify concerns about the impressions one makes on others as the precipitating factor in social anxiety. The model states that social anxiety occurs when a person is motivated to make a particular impression on others and doubts whether they will be able to do so, regardless of whether the impression is positive or negative, or positive or negative enough, relative to their expectations. The approach calls for an assessment of an individual's need for approval, level of social skill, level of selfesteem, and expectations about their own social behavior. By identifying and addressing gaps between expectations and actual performance, social anxiety may lessen. In the case of Night Owl, more therapeutic progress may have been made if his expectations for social performance had been addressed more directly. It is striking for example that he is able to perform well socially in professional contexts, but not in other contexts. He interprets this ability as "hiding behind the professional mask" (p. 226), but it could be re-conceptualized as a strength and as a set of skills he could extend from one sphere of his life to others. A pathway to doing so could be addressing his performance expectations in professional and non-professional contexts.

In sum, it appears that the best explanation for the different outcomes is that Daydreamer implemented the treatment more fully than did Night Owl. It is possible that a treatment that was more consistent with Night Owl's formulation of his social phobia and with his unique strengths may have benefited him more. 


\section{CONCLUSION}

This commentary has considered why one client's outcome was better than the other's in the papers on Online, clinician-guided CBT for panic disorder with agoraphobia and social anxiety disorder. What we found is that the less successful client in each case appeared less willing to relax safety mechanisms and to engage in graduated exposure exercises, supported by adaptive interpretation of the outcome of those exercises through the cognitive restructuring modules. This finding appears to be more pronounced in the case of Night Owl than Andrea.

Review of the extent to which common factors were implemented also suggested differences in the successful and unsuccessful outcomes, with the successful outcomes demonstrating more engagement of empirically supported common factors. These include acceptance of the treatment model and rationale, perceived self-efficacy, match between the clients' reactance and the treatment, and the attainment of success experiences to initiate virtuous curative cycles. One common factor that did not differentiate the outcomes was therapeutic alliance, which was high in all cases, suggesting that a strong therapeutic alliance may be a necessary but insufficient condition for success.

Overall, as indicated in the analyses above, the four case studies reveal rich interactions between the client and the therapist guide. The "computer" did not seem to block the clinical processes that are seen when only the client and therapist are involved in the treatment.

Finally, it is noteworthy that common and specific factors intertwined and in some cases, a common factor was embodied through a specific factor. For example, exposure is considered a specific technique, but it involves application of common factors such as appropriate risk taking, attainment of success experiences, and behavioral mastery.

The differences in outcome might be summed up in a quotation attributed to Julian Beck, Founder of the Living Theater in New York City, "The essential preparation is finding the courage” (C. Fauteaux, personal communication, 1978). Each of the more successful clients was able to find the courage to confront and begin to master their anxiety.

\section{REFERENCES}

Andrews, G. (2003). The treatment of anxiety disorders: Clinician's guide and patient manuals (2nd ed.). Cambridge: Cambridge University Press.

Arnberg, F. K., Linton, S. J., Hultcrantz, M., Heintz, E., \& Jonsson, U. (2014). Internet-delivered psychological treatments for mood and anxiety disorders: A systematic review of their efficacy, safety, and cost-effectiveness. PLoS ONE, 9(5), e98118. doi:10.1371/journal.pone.0098118

Barlow, D. H. (1988). Anxiety and its disorders: The nature and treatment of anxiety and panic. New York: Guilford Press.

Barlow, D. H. (2002). Anxiety and its disorders: The nature and treatment of anxiety and panic, (2nd ed.). New York: Guilford Press. 
Barlow, D. H., Allen, L. B., \& Basden, S. L. (2007). Psychological treatments for panic disorders, phobias, and generalized anxiety disorder. In P. E. Nathan \& J. M. Gorman (Eds.), A guide to treatments that work (3rd ed., pp. 351-394): Oxford University Press.

Bohart, A. C., \& Wade, A. G. (2013). The client in psychotherapy. In M. J. Lambert (Ed.), Bergin and Garfield's Handbook of Psychotherapy and Behavior Change (6th ed., pp. 219-257). New York: John Wiley \& Sons, Inc.

Ciuca, A.M., Berger, T., \& Miclea. M. (2017). Maria and Andrea: Comparing positive and negative outcome cases in an online, clinician-guided, self-help intervention for panic disorder. Pragmatic Case Studies in Psychotherapy, 13(3), Article 1, 173-216. Available: http://pcsp.libraries.rutgers.edu

Clark, D. A., \& Beck, A. T. (2011). Cognitive therapy of anxiety disorders: Science and practice. New York: Guilford Press.

Clark, D. M., \& Wells, A. (1995). A cognitive model of social phobia. In R. G. Heimberg \& M. R. Liebowitz (Eds.), Social phobia: Diagnosis, assessment, and treatment. (pp. 69-93). New York, NY, US: Guilford Press.

Craske, M. G., \& Barlow, D. H. (2014). Panic disorder and agoraphobia. In D. H. Barlow (Ed.), Clinical Handbook of Psychological Disorders: A Step-By-Step Treatment Manual (5th ed., pp. 1-61). New York: Guilford Publications.

Crits-Christoph, P., Gibbons, M. B. C., \& Mukherjee, D. (2013). Psychotherapy processoutcome research. In M. J. Lambert (Ed.), Bergin and Garfield's Handbook of Psychotherapy and Behavior Change (6th ed., pp. 298-340). New York: John Wiley \& Sons, Inc.

Eells, T. D. (2007). Generating and generalizing knowledge about psychotherapy from pragmatic case studies. Pragmatic Case Studies in Psychotherapy, 3(1), Article 3, 35-54. Available: http://pcsp.libraries.rutgers.edu

Fishman, D. B. (1999). The case for pragmatic psychology: New York, NY, US: New York University Press.

Fishman, D. B., Messer, S. B., Edwards, D. J. A., \& Dattilio, F. M. (Eds.). (2017). Case studies within psychotherapy trials:Integrating qualitative and quantitative methods. New York, NY: Oxford University Press.

Frank, J. D., \& Frank, J. B. (1991). Persuasion and healing: A comparative study of psychotherapy (3rd ed.). Baltimore, MD: The Johns Hopkins University Press.

Lambert, M. J. (2013). The efficacy and effectiveness of psychotherapy. In M. J. Lambert (Ed.), Bergin and Garfield's Handbook of Psychotherapy and Behavior Change (6th ed., pp. 169-218). New York: John Wiley \& Sons, Inc.

Leahy, R. L., \& Holland, S. J. (2000). Treatment plans and interventions for depression and anxiety disorders. New York: Guilford Press.

Leary, M. R., \& Kowalski, R. M. (1995). The self-presentation model of social phobia. In R. G. Heimberg, M. R. Liebowitz, D. A. Hope, \& F. R. Schneier (Eds.), Social phobia: Diagnosis, assessment, and trearment (pp. 94-112). New York: Guilford Press.

Martin, D. J., Garske, J. P., \& Davis, M. K. (2000). Relation of the therapeutic alliance with outcome and other variables: A meta-analytic review. Journal of Consulting and Clinical Psychology, 68(3), 438-450. doi:10.1037/0022-006x.68.3.438 
Milrod, B., Chambless, D. L., Gallop, R., Busch, F. N., Schwalberg, M., McCarthy, K. S., .. . Barber, J. P. (2015). Psychotherapies for panic disorder: A tale of two sites. Journal of Clinical Psychiatry, 77(7), 927-935.

Orlinsky, D. E., Grawe, K., \& Parks, B. K. (1994). Process and outcome in psychotherapyNoch einmal. In A. E. Bergin \& S. L. Garfield (Eds.), Handbook of psychotherapy and behavior change (4th ed., pp. 270-376). New York: John Wiley \& Sons, Inc.

Schulz, A., Vincent, A., \& Berger, T. (2017). Daydreamer and Night Owl: Comparing positive and negative outcome cases in an online, clinician-guided, self-help intervention for social anxiety disorder. Pragmatic Case Studies in Psychotherapy, 13(3), Article 2, 217 252. Available: http://pcsp.libraries.rutgers.edu

Scott, W. D., \& Cervone, D. (2009). Self-efficacy interventions: Guided mastery therapy. In W. T. O'Donohue \& J. E. Fisher (Eds.), General principles and empirically supported techniques of cognitive behavior therapy (2nd ed., pp. 488-493). Hoboken, NJ: John Wiley \& Sons Inc.

Stiles, W. B. (2009). Logical operations in theory-building case studies. Pragmatic Case Studies in Psychotherapy, 5(2), Article 2, 9-22. Available: http://pcsp.libraries.rutgers.edu

Suárez, L., Bennett, S., Goldstein, C., \& Barlow, D. H. (2008). Understanding anxiety disorders from a "triple vulnerabilities" framework. In M. M. Anthony \& M. B. Stein (Eds.), Oxford handbook of anxiety and related disorders (pp. 153-172). New York: Oxford University Press.

Williams, S. L. (1990). Guided mastery treatment of ogoraphobia: Beyond stimulus exposure. In M. Hersen, R. M. Eisler, \& P. M. Miller (Eds.), Progress in Behavior Modification (Vol. 26, pp. 89-121). Newbury Park, CA: Sage.

Williams, S. L., Dooseman, G., \& Kleifield, E. (1984). Comparative effectiveness of guided mastery and exposure treatments for intractable phobias. Journal of Consulting and Clinical Psychology, 52(4), 505-518. 